\title{
LOS PROFESORES DE CIENCIAS COMO PROFESORES DE LENGUAJE*
}

\author{
SUTTON, CLIVE \\ clive.sutton@btinternet.com
}

\begin{abstract}
Resumen. A fin de contribuir a las discusiones acerca de las políticas de educación científica, en este trabajo exploro un marco teórico para la enseñanza de las ciencias, la formación de profesores de ciencias y la investigación en didáctica de las ciencias que enfatiza el papel del lenguaje como herramienta interpretativa en situaciones nuevas. Mi aproximación está tomada de la historia de la ciencia y de los estudios sobre la estructura de la argumentación científica, que muestran que, cuando un área del pensamiento científico es nueva, el papel interpretativo del lenguaje es central. Las nuevas formas de «mirar» lo que sucede están estrechamente conectadas con nuevas formas de hablar sobre ello y con nuevas preferencias en los procedimientos de investigación. Entonces, si se desea que los estudiantes entiendan «qué hacen los científicos», se necesita que ellos se concentren en el lenguaje y en el experimento. De esta manera pueden desarrollar capacidades para hablar acerca de un tema científico cuando las imágenes, el discurso y el método van juntos. Se puede pensar en los profesores como guías que ayudan a los estudiantes a explorar estos sublenguajes de temas particulares, que han sido desarrollados por los científicos y que ahora discurren por nuestra cultura.

Palabras clave. Lenguaje científico, discurso en el aula, herramienta interpretativa, naturaleza de la ciencia.

Summary. As a contribution to discussions about science education policy, I explore in this presentation a rationale for science teaching, teacher training and research which emphasises the role of language as an interpretive tool in strange situations. My approach is drawn from history of science and from studies of the structure of scientific argument which show that when any area of scientific thought is new, the interpretive role of language is central. New ways of «seeing» what is going on are closely connected with new ways of talking about it and with newly preferred procedures for investigation. Hence, if learners are to understand «what scientists do», they need focus on the language as well as the experiment. In that way they can develop competence to speak about a scientific topic, when the imagery, speech and method all hang together. Teachers can be thought of as guides who help the pupils to explore these sublanguages of particular topics, which scientists have developed and which now permeate our culture.
\end{abstract}

Keywords. Scientific language, classroom discourse, interpretive tool, nature of science.

\section{LOS PROFESORES}

Cuando un profesor habla, ¿cuál es la función del discurso? ¿Es, por ejemplo, transferir información a los aprendices o es proveer un modelo sobre el cual ellos puedan construir su capacidad de hablar acerca del tema científico del que se trate? ¿Es controlar a los aprendices como grupo o es estimular su pensamiento? Desde luego, puede ser todas estas cosas al mismo tiempo. A veces el profesor es un experto «dando» conocimiento aceptado para que los estudiantes lo «reciban», y en ese caso él o ella está funcionando como un transmisor. Sin embargo, me interesa más la clase de discurso en la cual el profesor es un gestor de la actividad y de la discusión. Él o ella buscan provocar el pensamiento, animando a los estudiantes para que entren en los patrones de razonamiento y en los patrones de lenguaje que han sido desarrollados por ciertos grupos de la comunidad científica y para que luego hagan explícita su propia comprensión de las nuevas ideas. Entonces podemos pensar en el profesor no sólo como un gestor, sino también como una guía hacia mundos mentales que son nuevos para los estudiantes y que alguna vez fueron totalmente nuevos para la humanidad. Esto es a lo que me refiero cuando hablo de usar el lenguaje de una manera interpretativa. El contraste entre estos usos del lenguaje (por un lado, a fin de transmitir etiquetas preestablecidas para las cosas y, por otro lado, con el objetivo de interpretarlas) se explora con más detalle en el capítulo VII de mi libro Words, science and learning (Sutton, 1992). 


\section{LOS CIENTÍFICOS}

¿Qué hacen los científicos (o los «filósofos naturales») en sus investigaciones? Los estudiantes, por lo común, afirman que los científicos «hacen experimentos» $\mathrm{y}$ «descubren» cosas. Ellos «encuentran hechos». Si se necesita el lenguaje para algo, parece ser simplemente para que nos cuenten qué descubrieron. Ésta es una historia muy incompleta y engañosa de lo que hacen los científicos, ya que no se valora el papel del lenguaje en el entrejuego de ideas y pruebas y se omite su función en la construcción de las nuevas ideas. Los historiadores y estudiosos del lenguaje han mostrado que éste está fuertemente implicado en el proceso de génesis y formulación de las nuevas ideas.

Por lo tanto, para la educación científica presente y futura, necesitamos una historia más completa. ¿Podemos mostrar a los estudiantes algo más acerca de este proceso? Por ejemplo, los científicos:

- ven algunos aspectos del mundo de una forma nueva;

- hablan acerca de él de una forma diferente; y

- hacen cosas de nuevas maneras.

Al mismo tiempo tienen ideas y buscan pruebas para apoyar o contradecir esas nuevas ideas, se persuaden a sí mismos y a los otros de que ciertas evidencias son importantes, escriben de nuevas maneras, negocian qué vale la pena investigar y qué métodos deberían usarse. También consiguen apoyo financiero y otros tipos de apoyo para continuar por este camino.

\section{Primer ejemplo}

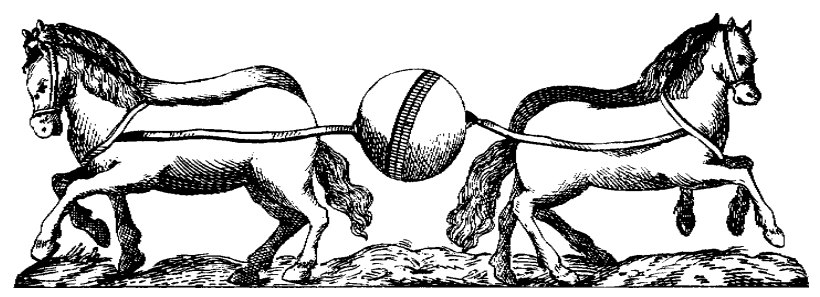

¿Qué se hizo en Magdeburgo? ¿Por qué se hizo? ¿Qué sentido tuvo para las personas involucradas? Necesitamos pensar acerca de cómo esas personas se estaban representando en su mente el aire y cuáles eran las nuevas maneras de estar hablando sobre él. Comenzaban a hablar de un material compresible y expansible, capaz de ser inyectado y expelido de contenedores. Comenzaba a existir una nueva rama del lenguaje, que incluía expresiones tales como más aire, menos aire, baja presión, alta presión, etc. El lenguaje estaba fuertemente inspirado en la imagen de Torricelli acerca de una cantidad limitada de este material sobre nosotros: «Vivimos en el fondo de un océano de aire.»

La nueva manera de mirar y la nueva manera de hablar sugirieron nuevas cosas para hacer, ya sea escalar montañas llevando un «barómetro» o hacer que unos caballos intenten separar hemisferios previamente «vacíados». En este nuevo mundo del pensamiento fue útil construir bombas, barómetros, contenedores esféricos con grifos, y así sucesivamente.

Quiero enfatizar que las ideas acerca de lo que significa hacer ciencia han cambiado mucho en las últimas décadas. La idea de los estudiantes acerca de que el descubrimiento es un proceso simple y el lenguaje es sólo un medio para contar lo nuevo es inadecuada. Para enseñar hoy en día la naturaleza de la actividad científica a los ciudadanos, deberíamos hacer énfasis en que equipos tales como microscopios, telescopios o espectrómetros no son tan importantes por sí solos. Hablar, «observar» y escribir es tan importante como manipular los aparatos. De alguna manera, el lápiz del científico es más importante que otro equipamiento de laboratorio.

\section{Segundo ejemplo}

¿Qué vio Lavoisier en su mente cuando eligió abandonar las antiguas formas de nombrar las sustancias y escribir nuevos nombres para éstas tales como oxyde de fer o sulfure d'argent? Al imaginar la combinación de «sustancias simples» para formar «sustancias compuestas», Lavoisier iniciaba la nueva práctica de pesar las sustancias antes y después de una reacción. El cambio químico era en este sentido una derivación de la nueva forma de hablar. El profesor que hoy enseña a sus estudiantes la importancia de este cambio y del equilibrio químico debe también educar sus mentes con imágenes relacionadas de «combinación» y «descomposición» y entrenarlos en la construcción de frases en las cuales dichos términos tienen sentido. Si tiene éxito, el profesor habrá llevado a sus estudiantes a través de una revolución cultural y lingüística. La forma en que sustantivos abstractos como descomposición se vuelven importantes en una nueva área del lenguaje científico ha sido explorada por Halliday y Martin (1993) en el capítulo I de su libro Writing science.

\section{Tercer ejemplo}

¿Cómo hablamos acerca del corazón y de la sangre actualmente? ¿Cómo los vemos? Para los ojos modernos, es difícil ver el corazón como algo más que una bomba para la

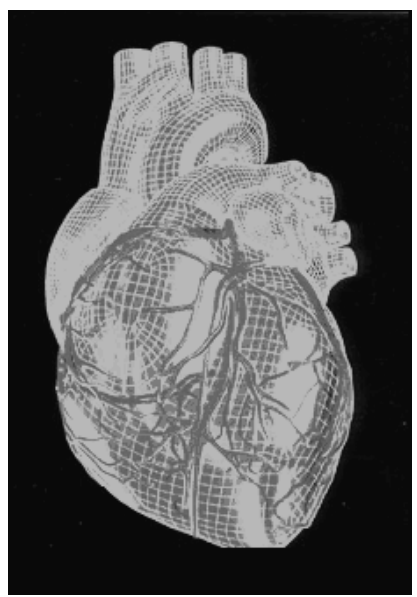


sangre, con entradas y salidas, componente central del sistema circulatorio.

Sin embargo, aun cuando estas ideas eran nuevas, estaban en uso formas de hablar desfasadas -por ejemplo, referirse al corazón como el sol del cuerpo. Esta expresión tiene poco significado para nosotros actualmente porque en un tiempo relativamente breve, a mediados del siglo XVII, se abandonó en favor de el corazón como una bomba.

Hablar sobre el flujo hacia adentro y hacia afuera de la bomba y sobre válvulas que permiten o impiden ese flujo en una dirección particular generó especulaciones acerca de la estructura plausible de otras partes del cuerpo. Recogiendo las mejores metáforas disponibles, Harvey escribió que la sangre «entraba en los tejidos como en una esponja» y luego «se escurría de ellos como el agua en un pantano». Este discurso motivó una investigación más detenida de este «pantano» usando microscopios, y poco después fue posible ver y hablar de «vasos capilares» como conexiones en el hipotético circuito de flujo.

\section{Cuarto ejemplo}

¿Cómo vemos la Tierra hoy en día? ¿Cómo hablamos de ella?

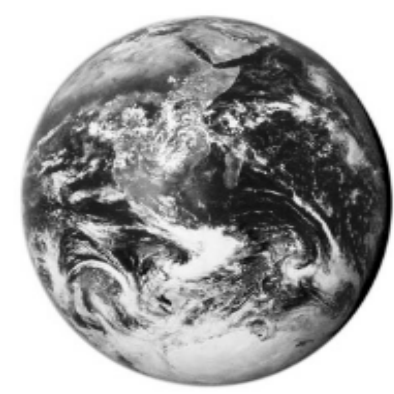

Vemos la «corteza» de la Tierra como un sistema de «placas tectónicas» móviles, con «zonas de subducción», «dorsales oceánicas» y «expansión del suelo oceánico» dentro de lo que hoy llamamos la «geósfera».

Vemos los océanos y lo que está sobre ellos como «hidrosfera, biosfera, atmósfera». Distinguimos un «ciclo del agua». El discurso científico acerca de la Tierra, con su surtido de sustantivos, transforma un proceso como «el agua fluyendo» en un objeto de estudio específico.

\section{La eliminación gradual de la provisionalidad}

Podemos resumir lo que los científicos hacen con el lenguaje diciendo que en el proceso de creación de la ciencia se van conectando entre sí nuevas formas de observar, hablar y hacer, y éstas se mantienen unidas mediante argumentaciones basadas en pruebas; pero lo que se considera una prueba cambia a medida que el sistema de habla evoluciona. En las etapas tempranas, las nuevas expresiones son conscientemente figurativas e interpretativas: «pensemos en el aire que nos rodea como en una especie de océano», «consideremos el corazón como una especie de bomba». Los recursos culturales para el desarrollo de una nueva idea científica usualmente incluyen patrones de discurso tomados de tecnologías importantes en la época, y las bombas eran un utensilio central en el siglo XVII. La transferencia metafórica de discurso al sistema que se investiga es lo que inicia un avance en el pensamiento. Referirse al aire como un océano o al corazón como una bomba comienza sólo como «una forma de decir», pero enseguida se acumulan pruebas y la naturaleza figurativa se desvanece. La comunidad científica a su debido tiempo tiene éxito en cambiar de «el corazón como una bomba» a «el corazón es una bomba».

En esta segunda etapa comienza a parecer que nunca ha habido ninguna duda. Las luchas mentales para comprender y explicar son olvidadas, y la explicación científica suena como una descripción literal de hechos simples. Los libros de texto escolares, al dar cuenta del hecho de segunda o tercera mano, son particularmente proclives a dar la impresión de un hecho simple hallado fácilmente. Esta mala interpretación de la ciencia está bien descrita en el libro de Rosalind Driver y otros (1996) titulado Young people's images of science.

Me parece que una parte importante de la educación científica debería orientarse a ayudar a los estudiantes a recuperar algunas de las luchas pasadas y a oír las voces auténticas de aquéllos que participaron en el proceso de formular una nueva forma de pensar.

Esto requeriría que fuéramos más tolerantes con las ideas incorrectas y con las teorías erróneas que parecían suficientemente razonables en su momento -como la idea del «calórico» como un fluido que pasa de un objeto caliente a otro más frío. Las ideas románticas siguen siendo ideas humanas y, ya sea que «veamos gigantes» o sólo «molinos de viento», el poder interpretativo humano está funcionando.

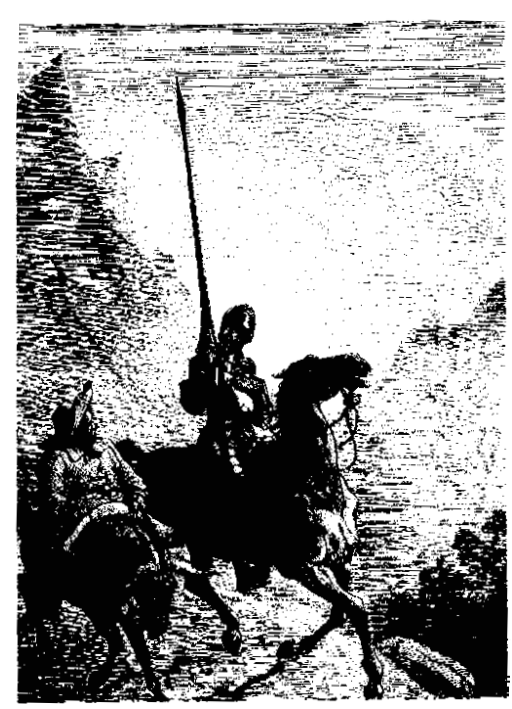




\section{LOS ESTUDIANTES}

¿Qué están haciendo los estudiantes en clase? ¿Podemos ayudarlos a darse cuenta del papel interpretativo del habla y la escritura? ¿Están aprendiendo a «ver» la imagen mental que los científicos han desarrollado? ¿Están aprendiendo a hablar sobre ella, entrando así en un nuevo mundo de discurso? ¿Están aprendiendo qué hacer en la práctica en este nuevo mundo de discurso?

Cuando les damos algo para leer, ¿están leyendo la forma de rastrear las ideas, el mundo mental y las pruebas del escritor? Dicho coloquialmente: ¿de qué hablaba el autor y cuáles eran las pruebas?

Cuando les pedimos que escriban, ¿lo hacen de una manera interpretativa, explorando ese mundo y razonando sobre él?

En esta pintura, el artista nos muestra a un joven que accede a nuevas conversaciones en el campo de la química.

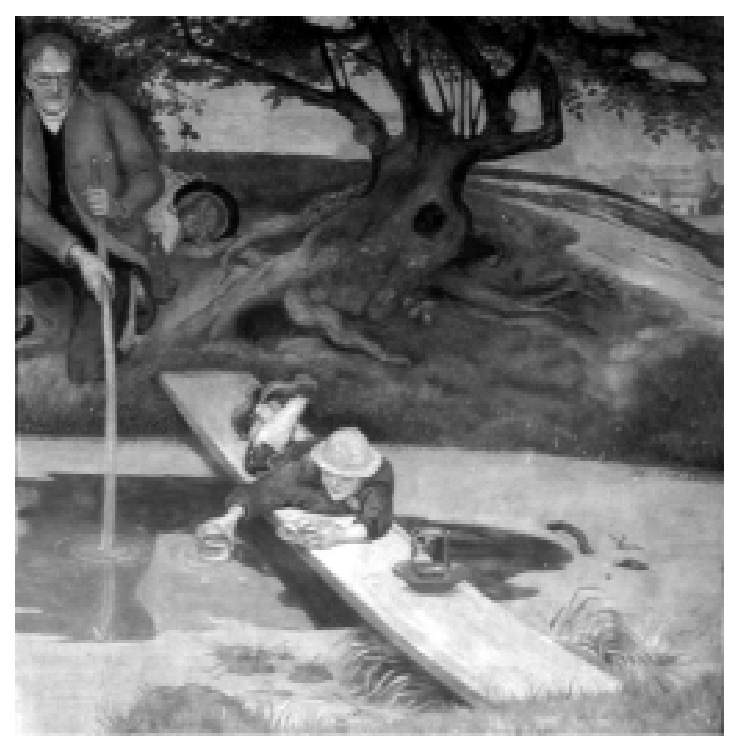

Un muchacho está con John Dalton recogiendo gas de los pantanos de una charca cerca de Manchester, en Inglaterra, alrededor de 1808. En ese tiempo, el discurso acerca de diferentes «gases» estaba comenzando a reemplazar referencias anteriores a aires y «vapores elásticos aeriformes». Los nombres de grisú y gas de los pantanos eventualmente ceden paso a metano, una sustancia particular, considerada una más entre los hidrocarburos.

Quizás este joven estaba aprendiendo qué decir en esas conversaciones y qué hacer en ese nuevo mundo de discurso.
En nuestro currículo nacional para el 2000 (Inglaterra), está escrito que se debería enseñar a los estudiantes cómo los científicos trabajan hoy en día y cómo trabajaban cómo en el pasado [...] incluyendo el papel de la experimentación, las pruebas y el pensamiento creativo en el desarrollo de las ideas científicas. (Las cursivas son mías.)

Sin embargo, los estudiantes todavía pueden adquirir una imagen distorsionada de la ciencia como actividad y de la ciencia como cuerpo de conocimiento, a menos que se preste atención a la manera cómo cambia el lenguaje a medida que la ciencia crece. Para contrarrestar esto, los estudiantes necesitan acceder a las «voces auténticas» de los científicos cuando están pensando ideas nuevas.

Para ilustrar todo eso con detalle se necesitaría más que este artículo, pero, como un pequeño ejemplo, podemos tomar la historia del «viaje en el pensamiento» de Charles Darwin sobre los cambios que se han producido en las rocas y en los seres vivos. Este tema lo tuvo ocupado no sólo durante su viaje alrededor del mundo, sino también durante veinte años de discusión y correspondencia posteriores.

En 1859, Darwin manifestó su posición en términos de ideas en el prefacio de su gran libro, de esta forma:

«Cuando estaba a bordo del Beagle como naturalista, me sorprendieron mucho ciertos hechos en la distribución de los seres vivos que habitan Sudamérica, y en las relaciones geológicas entre los habitantes presentes y pasados de ese continente. Estos hechos [...] parecían arrojar algo de luz sobre el origen de las especies -ese misterio de misterios. Al regresar a casa, se me ocurrió que se podía sacar algo de esta cuestión.»

Un estudio de caso más completo de este episodio revela que, mientras Darwin estaba «deduciendo algo de la cuestión», emergía un nuevo lenguaje acerca del cambio gradual, primero entre los geólogos que trabajaban sobre las rocas y luego aplicado por el propio Darwin al cambio gradual en los seres vivos. Hablar sobre «selección»-selección artificial al principio- llevó por analogía a la «selección natural», y a su debido tiempo una parte sustancial de la comunidad profesional quedó persuadida de que ésta era una forma útil de hablar, apoyada por pruebas apropiadas.

Alguna cosa más del proceso del pensamiento de Darwin es accesible a partir de su voluminosa correspondencia, y la tendencia actual entre los historiadores de la ciencia es sacar a la luz el contexto en el cual estas nuevas ideas y formas de hablar tenían sentido. Si esta forma de representar la ciencia puede hacerse más ampliamente accesible en la escuela, será más fácil para los profesores de ciencias cumplir con su papel de profesores de lenguaje.

\section{NOTA}

* Ponencia presentada en el VI Congreso Internacional sobre Investigación en la Didáctica de las Ciencias (Barcelona, 12 al 15 de septiembre de 2001). Ha sido traducida del inglés por Agustín Adúriz-Bravo. 


\section{REFERENCIAS BIBLIOGRÁFICAS}

BAZERMAN, C. (1988). Shaping written knowledge. Madison: University of Wisconsin Press.

BROWNE, J. (1995). Charles Darwin voyaging. Londres: Pimlico.

DEAR, P. (ed.) (1991). The literary structure of scientific argument. Madison: University of Pennsylvania Press.

DRIVER, R., LEACH, J., MILLAR, R. y SCOTT, P. (1996). Young people's images of science. Bristol: Open University Press.

HALLIDAY, M.A.K. y MARTIN, J.R. (1993). Writing science. Londres: Falmer.
LEMKE, J. (1990). Talking science. Norwood: Alex Publishing Co.

MYERS, G. (1990). Writing biology. Madison: University of Wisconsin Press.

SUTTON, C. (1992). Words, science and learning. Buckingham: Open University Press.

SUTTON, C. (1997). Ideas sobre la ciencia e ideas sobre el lenguaje. Alambique, 12, pp. 8-32.

SUTTON, C. (1998). Science as conversation, en Wellington, J. (ed.). Practical work in school science: which way now? Londres: Routledge. 